\title{
A PRODUÇÃO DO SALITRE NO BRASIL COLONIAL
}

Márcia Helena Mendes Ferraz

Programa de Estudos Pós-Graduados em História da Ciência - Pontifícia Universidade Católica de São Paulo - Rua Marquês de Paranaguá, 111, prédio I - 01303-050 - São Paulo - SP

Recebido em 4/10/99; aceito em 18/4/00

\begin{abstract}
THE PRODUCTION OF SALTPETER IN COLONIAL BRAZIL. This article discusses the processes inherent in the production of salpeter in Colonial Brazil. In the main, the texts seen here present recipes accompanied by chemical explanations of the processes which denote a knowledge of science at the time. Various difficulties confronting the authors, however, prevented an effective contribution to the development of techniques for the production of salpeter. Consequenttly, at the end of the Nineteenth Century, Brazilian rulers are still facing many problems to obtain this precious material.
\end{abstract}

Keywords: history of chemistry; science in Colonial Brazil; natural resources; saltpeter.

A utilização do salitre como fertilizante e, ainda, como matéria-prima para a produção industrial de ácidos é objeto mais recente. Entretanto, sua importância na fabricação de materiais explosivos é sobejamente conhecida desde muito tempo e mereceu o cuidado dos governos preocupados, em maior ou menor extensão, com a defesa de seus domínios. Tratavase, por um lado, da obtenção de umas das matérias-primas básicas para a produção da pólvora e, por outro, da fabricação da pólvora própriamente dita e do aperfeiçoamento de sua eficiência destrutiva.

Para ficarmos em poucos exemplos situados no período que queremos discutir, lembremo-nos dos trabalhos realizados na segunda metade do século XVIII no Arsenal de Paris por pensadores proeminentes como L. -B. Gutyton de Morveau, P. -J. Macquer e C. -L. Berthollet, assim como na Administração da Pólvora e do Salitre, onde vamos encontrar A. -L. Lavoisier. Esses trabalhos, por sua importância, já renderam estudos de diversos historiadores da ciência abordando os aspectos da produção e das explicações químicas para os processos envolvidos. Acabaram por receber de um historiador francês, por uma analogia com a chamada "Revolução Química", o epíteto de "Revolução da Pólvora"1.

Um outro exemplo que merece ser comentado liga-se mais diretamente ao nosso passado político. Senão vejamos. Como sabemos, ao mudar-se para o Brasil em 1808, o governo português deixou a Metrópole entregue ao destino que poderiam dar-lhe os súditos que lá foram obrigados a ficar. Não faltou empenho, sem dúvida, e a história registra atividades que buscavam defender o extremo da Península Ibérica da ação dos franceses invasores, como são os trabalhos desenvolvidos pelo corpo universitário de Coimbra, fosse na formação de um batalhão composto por alunos e professores, fosse na fabricação dos cartuchos para suas armas. Também a pólvora foi aí preparada, ocupando todos os meios de que dispunha o Laboratório Químico da Universidade ${ }^{2}$. Até onde sabemos, pouco salitre estava disponível em Portugal e o governo mandou recolher por toda parte o que fosse encontrado, tornando ainda mais escasso o material. Mesmo a Casa da Moeda - onde o salitre era fundamental para a manipulação de metais preciosos - encontrou problemas para desenvolver as atividades que utilizavam esse material ${ }^{3}$.

Centro Simão Mathias de Estudos em História da Ciência/PUC-SP - CESIMA; e-mail: cesimahc@pucsp.br; FAPESP - Fundação de Amparo à Pesquisa do Estado de São Paulo
Na Universidade de Coimbra, a fabricação da pólvora esteve a cargo de Tomé Rodrigues Sobral, então o catedrático de Química e, como tal, também diretor do Laboratório Químico. Conta-se que os franceses, uma vez tendo dominado Coimbra, quiseram saber o nome do responsável pela fabricação dos explosivos utilizados pela Armada Portuguesa que tantos estragos haviam causado em suas tropas. Ato seguinte, como represália, incendiaram a residência do professor de Química. Pela significância dos episódios relatados, Sobral acabou ganhando as páginas da história como "mestre da pólvora"4.

Voltando à nossa questão principal, vejamos o que se considerava, nesse período, as fontes dos materiais nitrogenados, que dariam o salitre, utilizado nos processos de fabricação da pólvora. Basicamente, três fontes poderiam ser enumeradas: 1) as salitreiras naturais, de cujas "terras" apenas se separava o salitre; 2) as salitreiras artificiais, onde se produziam as "terras" que dariam o salitre e, 3) o ar, fonte de nitrogênio, um dos componentes do ácido nítrico, passo fundamental para a obtenção do tão desejado material.

Vamos discutir cada um desses casos, no que respeita ao Reino Português, expondo alguns exemplos. Trataremos de discutir também, quando couber - e quando houver dados disponíveis - as idéias químicas envolvidas.

\section{AS SALITREIRAS NATURAIS}

As orientações dos governantes portugueses a seus representantes nas colônias, no período em questão, destacavam a importância do envio das descrições dos materiais que poderiam ser explorados para o lucro da Metrópole. Essa atitude é intensificada a partir da Reforma da Universidade de Coimbra, quando se introduziram formalmente os estudos das ciências naturais ${ }^{5}$.

Assim, os reinos vegetal, animal e mineral deveriam ser vasculhados, descritos, analisados, classificados. O aproveitamento dos produtos e a instituição de suas fábricas deveriam também ser contemplados nas memórias dos viajantes, como se pode ler nas instruções dadas a Alexandre Rodrigues Ferreira, por exemplo, antes de sua longa viagem pelo Brasil entre 1782 e $1793^{6}$.

Como parte do reino mineral, também o salitre deveria ser "estudado", ou seja, os chamados "viajantes naturalistas" deveriam relacionar os locais de onde se poderia extrair o material, além de indicar os detalhes do processo. Este seria, basicamente o seguinte. Começava-se por acondicionar em tonéis, camadas da terra de que se pretendia extrair o salitre alternadas com outras de cinza, e, algumas vezes, com camadas de palha adicionadas para facilitar a passagem da água. Fazia-se 
uma cova na parte superior deste arranjo, onde se adicionava potassa (nosso carbonato de potássio), para em seguida, colocar água. Passado algum tempo, deixava-se escorrer (através de torneiras ou de orifícios até então tampados) a água, carregada de salitre, que era levada a evaporar em caldeiras. Durante o processo de evaporação, retirava-se, com uma escumadeira, a massa de sal comum (nosso cloreto de sódio) que se vai formando, até se ter apenas o líquido. Continuava-se até evaporação total, quando se tinha, finalmente o salitre "bruto ou impuro", que seria ser refinado posteriormente ${ }^{7}$.

As memórias elaboradas pelos viajantes naturalistas a serviço da Corôa destinavam-se, muitas vezes, apenas aos governantes que podiam determinar políticas de exploração das "produções naturais". Uma outra possibilidade era virem à luz através das publicações da Academia Real das Ciências de Lisboa, o que de fato aconteceu com um certo número de trabalhos $^{8}$. Restava ainda, dentro de um projeto de divulgação ampla, as publicações realizadas a partir de finais do século XVIII pela Tipografia Calcográfica e Literaria do Arco do Cego (entre 1799-1801) ou por sua sucedânea, a Imprensa Régia, instituições dirigidas pelo Frei José Mariano da Conceição Veloso (1741 ou 1742-1811), natural de Minas Gerais.

Veloso desempenhou importante papel na divulgação de trabalhos sobre as ciências naturais, com destaque para as atividades que poderiam ser desenvolvidas no Brasil, como a agricultura, a criação de animais, a instalação de algumas fábricas e a mineração. Tratava-se, principalmente de memórias e "cartas" a ele enviadas, mas, também, de traduções feitas, muitas vezes, por ele mesmo?.

No campo das traduções Frei Veloso realizou várias coletâneas de memórias de estudiosos estrangeiros sobre um mesmo assunto, como foram a Alographia dos alkalis vegetal ou potassa, mineral ou soda e dos seus nitratos, a Quinografia Portuguesa ou collecção de varias memorias e o Mineiro do Brasil. Outras referem-se a diversos assuntos, como é o caso do Fazendeiro do Brasil ${ }^{10}$.

Merece comentário, ainda que breve, o texto denominado Alographia (tratado dos sais), em que o "editor" pretendia fornecer subsídios para a fabricação de potassa (nosso carbonato de potássio), de soda (nosso carbonato de sódio) e de salitre (nosso nitrato de potássio). Pensava, assim, estar respondendo às necessidades das "Saboarias, vidrarias, tinturarias, Branquearias, á Agricultura, á Chymica, a Pharmacia, \&c"11. Pretendia disponibilizar um manual completo, suficiente para indicar aos leitores, mesmo que distantes da Metrópole, as operações básicas para o desempenho de suas atividades no aproveitamento das produções naturais.

Veloso, no entanto, não parece ter alcançado seus objetivos, pois materiais como este tiveram pequena divulgação entre $o$ público a que se destinava, apesar de os temas serem de fundamental importância para várias atividades produtivas que $\mathrm{O}$ governo pretendia ver desenvolvidas na América portuguesa ${ }^{12}$.

No mesmo período em que Veloso faz publicar esses textos, encontramos outro "brasileiro", João da Silva Feijó (17651815), nascido no Ri de Janeiro e formado pela Universidade de Coimbra, dedicando-se ao reconhecimento das colônias portuguesas. Ele foi designado pelo governo para trabalhar em Cabo Verde, ocupando o cargo de naturalista durante vários anos. No início do século XIX encontrava-se em Fortaleza, realizando trabalhos em nitreiras e coletando plantas e minerais. Alguns dos textos elaborados por Feijó vieram a público nas Memórias Económicas da Academia Real das Ciências de Lisboa e em $O$ Patriota - periódico publicado no Rio de Janeiro entre 1813 e 1814 -, sendo que alguns textos encontram-se, ainda, inéditos. A abordagem de alguns de seus trabalhos nos mostra uma interposição de explicações anteriores e posteriores à Revolução Química, refletindo o contexto das discussõoes sobre a ciência da matéria no período ${ }^{13}$.

Nesse quadro, chama-nos a atenção um episódio ocorrido no início do século XIX, envolvendo os trabalhos de Feijó na produção de salitre. Para apresentá-lo, lançamos mão principalmente de dois documentos. O primeiro, escrito em Lisboa em 1801, foi denominado pelo Arquivo Nacional do Rio de Janeiro de "Relatório de Charles Napion sobre reações químicas em vários minerais" "14. O segundo documento, datado de 1803, e do punho de Feijó, encontra-se no Arquivo Histórico da Casa da Moeda de Lisboa. Trata-se de uma longa carta seguida de um relatório das despesas efetuadas para a instalação e funcionamento do Real Laboratório da Refinação do Salitre no Ceará ${ }^{15}$.

Feijó fala detidamente de suas atividades à frente da produção do salitre, fazendo referência também a outras incumbências, como a de preparar sementes e exemplares vivos de plantas para o Real Jardim Botânico da Ajuda, em Lisboa. Ele lamenta as dificuldades encontradas para levar à frente um empreendimento que já durava 27 meses sem poder ao "menos aproveitar mil alqueires de cinza e setecentos de terra nitrogenada" então reservadas para a produção do salitre ${ }^{16}$. Por se tratar de um relatório, Feijó apresenta detalhes sobre os preços dos materiais e utensílios, custo da mão-de-obra, quantidades produzidas e demais questões afeitas a suas atividades. Dessa forma, ficamos sabendo que a "safra" do ano anterior havia sido menor que a esperada devido à seca e à fome; e que toda uma carga de cerca de 50 arrobas, enviada a Portugal, havia voltado a seu ponto de origem, com o salitre "avariado pella Agoa do Mar"17.

De fato, depreende-se do documento que a situação de Feijó não é confortável, pelos azares da vida. Até mesmo o governador do Ceará havia morrido recentemente e Feijó via modificarem-se os rumos de suas atividades por não ter conseguido alcançar a simpatia dos governadores interinos. Parece-nos que Feijó já não tinha a proteção dos representantes do governo português em terras brasileiras para obter os recursos necessários à continuação dos trabalhos nas salitreiras. Procurando não demonstrar o insucesso na execução de seus projetos, Feijó alega falta de saúde - depois de 23 anos servindo a Corôa -, pede afastamento das atividades que desenvolvia e solicita um outro cargo menos desgastante ${ }^{18}$.

Em seu relato Feijó refere-se "a nota do Cavalheiro Napion sobre a sua analize do salitre que constituiu a minha primeira remessa"19. E isso faz a conexão com o outro documento acima mencionado. Conforme palavras do próprio Napion, ele recebera a incumbência da analisar uma amostra de salitre do Ceará e teria chegado a conclusões desabonadoras quanto ao trabalho realizado por Feijó no nordeste do Brasil. Segundo o método utilizado por Napion, a quantidade de "muriato de soda" (nosso cloreto de sódio) presente na amostra deveria indicar a qualidade do salitre e os resultados a que chegara seriam os correspondentes a um salitre de segunda categoria. Ou seja, Feijó não havia realizado com o cuidado necessário a purificação ou refinação do salitre, sendo o produto, portanto, muito inferior ao que imaginava estar enviando para análise. Napion chega a ironizar as informações de Feijó quanto à riqueza em salitre das terras nitrogenadas. Duvida também da eficácia do método então utilizado, pois ao supor que todo salitre seria de base terrosa, Feijó estaria adicionando cinza em excesso (a cinza seria a fonte de potassa). Acontece que Feijó sobrevaloriza, no custo final do salitre, o valor corespondente à cinza e, como observa Napion: "eu não consigo entender como as cinzas podem custar tanto como pretende nosso Senhor Feijó, num país onde a madeira aparentemente não custa nada, pois ele não a menciona em suas notas de despesas." De qualquer forma, encontramos alguns autores que não utilizam cinzas (ou criticam seu uso) no processo de obtenção do salitre quando se trata de salitreira naturais ${ }^{20}$. Também a terra nitrogenada parece a Napion sobrecotada e se, de fato, elas valem o que Feijó relata, elas seriam, segundo Napion "de uma riqueza surpreendente" em salitre; assim ele pede esclarecimentos sobre "a qualidade e quantidade das 
terras nitrogenadas, a maneira como é encontrada e explorada e a distância em que ela se encontra da fábrica de salitre". Com esses dados Napion esperava poder "fazer uma avaliação sobre a utilidade que se pode esperar dessas nitreiras naturais, e sobre o tratamento mais conveniente" ${ }^{\text {. } 1}$.

Napion, de sua parte, utiliza em seu relatório, os argumentos da ciência química do período, descrevendo com certos detalhes a marcha das análises que realizou. Baseando-se nos resultados obtidos, ele manifesta sua discordância quanto aos dados enviados por Feijó e, de certa forma, procura expor ao ridículo a formação do "químico brasileiro". Conforme dissemos mais acima, Feijó interpõe, em outros trabalhos, idéias da "velha" e da "nova" química em suas explicações; daí, talvez, a discordância de Napion quanto aos aspectos técnicos do trabalho realizado no Brasil.

Praticamente dois anos separam a solicitação de Napion e o relatório de Feijó discutido acima. No ano de 1802, período que medeia a elaboração dos dois documentos, Napion é nomeado responsável pelas fábricas de pólvora do Reino ${ }^{22}$. Podemos pensar que sua posição e autoridade teriam contado na hora de se interferir na continuidade dos trabalhos de Feijó. Entretanto, Feijó não parece ter-se dado por vencido. Aproveitando-se da ausência de um dos membros do governo interino do Ceará, conforme relata o próprio Feijó ${ }^{23}$, consegue que lhe seja destinado o numerário necessário para manter em marcha os trabalhos de produção de salitre. Parece que a autoridade de uma decisão técnica sobrevivia apenas o tempo de ida e volta de um navio da Metrópole... Entretanto, o salitre produzido nessa fábrica tinha um preço muito mais alto do que aquele preparado em outras localidades e mesmo do que o estrangeiro. Assim, em 1806 o governo põe fim às pretensões Feijó, determinando o fim da exploração do salitre na fábrica do Ceará ${ }^{24}$.

\section{AS NITREIRAS ARTIFICIAIS}

Após termos discutido os trabalhos relativos às chamadas nitreiras naturais, vamos nos dedicar a apresentar o que seriam as nitreiras artificiais. Para tanto, nada melhor do que abordar os trabalhos de um outro "brasileiro": José Vieira Couto, nascido em 1752. Formado em Filosofia Natural pela Universidade Coimbra, em 1778, desempenhou, durante um período, as funções de professor dessa instituição. Posteriormente, foi designado pela rainha, D. Maria I, para percorrer a região ao norte da Capitania de Minas Gerais, sua terra natal ${ }^{25}$.

Couto elaborou vários textos, entre eles a "Memória sobre a Capitania de Minas Gerais", onde vemos expostas descrições das salitreiras encontradas em suas viagens de reconhecimento da região ${ }^{26}$. Entretanto, considerando os objetos deste trabalho, merece destaque sua "Memória sobre as salitreiras de Monte Rorigo: maneira de as auxiliar por meio das artificiaes; refinaria do nitrato de potassa, ou salitre", onde encontramos descritos mais amplamente os aspectos da produção do salitre e, ademais, vemos discutidas as questões relativas à composição e à transformação da matéria ${ }^{27}$.

Ao tratar das salitreiras naturais, na primeira secção, a principal preocupação de Couto era de que o salitre depositado "naturalmente" nas cavernas que visitou em Monte Rorigo pudesse esgotar-se num futuro muito próximo. Couto notara que nesses lugares, ao se cavar "mais profundamente, que exceda os dois palmos pouco mais ou menos, já não se topam os nitratos"28. Para agravar a situação, o processo utilizado deveria levar à falta do sal, pois, retirava-se das cavernas a porção da matéria (terras e estalactites porosas que deveriam conter o sal), procedia-se à lavagem para obtenção do sal - segundo o processo que descrevemos acima - e, em seguida, jogava-se-as fora. Esse material, se fosse mantido nas cavernas, levaria à deposição de mais salitre, diz nosso autor. Talvez ele estivesse pensando, como Feijó, numa nova "safra" ao afirmar que "estas terras, já apropriadas pelas mãos da natureza para atrahirem este sal, e como ja encerrando em si (permita essa expressão) o fermento da sua producção", deveriam ser repostas nas cavernas "onde em pouco tempo se tornariam a impregnar, e talves ainda mais do que d'antes, do mesmo salitre" 29 .

Uma segunda maneira de evitar a falta de salitre é apresentada na secção seguinte, no que seria um projeto para a construção de salitreiras artificiais. Essa pretensão, segundo nosso autor, era plenamente justificável, pois, existia uma grande semelhança entre as condições das salitreiras artificiais e aquelas das cavernas descritas. Ele pôde, dessa forma concluir que a origem dos nitratos de Monte Rorigo era a mesma daquele produzido nas salitreiras artificiais. A diferença estaria em que as salitreiras artificiais eram construídas pelas "mãos dos homens, e o nitrato [era] ahi produzido á custa da indústria humana"30. Equivalendo-se as duas maneiras de formação do salitre, caberia decidir apenas sobre a que seria mais adequada ${ }^{31}$.

Couto, no entanto, considera que a melhor maneira de "formar" o salitre, seria na salitreira artificial, que, segundo o autor, "não é outra cousa mais do que uma casa palhoça, debaixo da qual se ajuntam certas quantidades de terras, que maneadas de certo modo se impregnam abundantemente de nitrato de potassa, ou salitre." Couto segue expondo a forma de construir as salitreiras, numa riqueza de detalhes que tornariam este artigo muito extenso se quiséssemos reproduzi-los. De qualquer forma, deveriam ser construídos tanques onde se depositavam os materiais "salitrificáveis" que, tratados de forma adequada, depois de um certo período dariam o precioso sal. Antes, porém, de passar à "receita" propriamente dita, Couto diz ser importante que o "salitreiro" saiba que: "o nitrato de potássio, este sal cuja producção e colheita é o objecto das suas lidas, é composto de tres principios, oxygeneo, azoto, e potassa : a combinação dos dois primeiros constitue o acido nitrico, e este ao depois com a potassa o dito nitrato ou salitre",32.

$\mathrm{O}$ azoto poderia ser obtido, como já há muito se sabia, de materiais de origem animal e vegetal, nos quais podia ser encontrado em grande quantidade. Ou seja:

"geralmente todas as terras a que se chamam estrumes, [...] as terras negras que se tiram dos logares escuros, como debaixo dos sobrados, e sobre tudo se ahi habitam animaes, ds adegas, cavalhariças [...] são tambem boas as terrras negras que estão por baixo das arvores copadas, [...] as terras dos cemiterios, dos curraes, principalmente das ovelhas, dos gallinheiros, pombaes, dos paioes de milho, [...] a lama das povoações, das latrinas, charcos, e alagoas..."

Se o salitreiro não dispuser de terras dos tipos listados, pode formar a sua terra juntando num buraco "todos os lixos do terreiro", a que se adicionam diversas espécies de plantas, além de "partes de animais, [...] as mais proprias para a nitrificação [...] as partes molles, como musculos, tripas, e seus conteudos, e o sangue". Pensamos que a citação acima é suficiente para mostrar que Couto pretendia dar todos os detalhes para a construção das salitreiras artificiais... Para tornar os resultados mais efetivos, nosso autor recomenda - seguindo, uma vez mais, uma antiga receita -, "regas" das salitreiras com águas de estrumes ou ainda aquelas que "vem de esgotos e cannos das ruas e latrinas, a que se misturou com sangue de animais, urinas, \&c" 33 .

Depois de tratar das terras produtoras do azoto, nosso autor passa a falar dos outros componentes do salitre. Senão vejamos. A potassa, poderia também ser obtida da mesma terra vegetal utilizada nas salitreiras como fonte de azoto; entretanto, parece a Couto que seria melhor adicionar cinzas de vegetais, a lixívia ou, ainda, a própria potassa ${ }^{34}$. Outro material necessário à formação do salitre era a "terra calcarea", empregada "solta e porosa, para melhor embeber em seus poros o acido, e formar o nitrato de cal" 35 .

Procurando explicar como ocorrem as reações químicas na produção do salitre, Couto se vale das idéias de afinidade ou atração. Também estão representadas as idéias da nova Química 
do oxigênio (o "formador de ácidos"), ao considerar o ácido nítrico como o produto da combinação de azoto e de oxigênio ${ }^{36}$.

Couto não estava solitário em seu interesse pela produção artificial do salitre, encontrando um "parceiro" em outro "brasileiro", João Manso Pereira (c. 1750-1830), que viu publicada sua Cópia de uma carta sobre a nitreira artificial estabelecida na Villa de Santos, da Capitania de São Paulo ${ }^{37}$. Nesse caso as principais "matérias primas" seriam o "pó" de sepultura e/ ou urina (para obtenção do ácido nítrico) e árvores do mangue (que, queimadas, dariam cinzas ricas em potassa).

\section{O AR}

$\mathrm{O}$ ar seria mais uma das fontes de materiais para a preparação de compostos nitrogenados. Longe de ser um sonho cuja concretização só viria a ocorrer no início do século $\mathrm{XX}$, essa idéia estava solidamente alicerçada nos trabalhos de A.-L. Lavoisier e seu grupo. Senão vejamos.

Fundada nos processos de análise e de síntese, a "Nova Química" definia a forma de operar a matéria e também a elaboração teórica. O entusiasmo pelos resultados já apresentados fazia acreditar que a realização dos projetos era apenas questão de tempo. No que se refere ao reino mineral, o futuro se mostrava ainda mais próximo e apenas questões técnicas pareciam separar as metas do sucesso num projeto. Nessa linha, encontramos a memória de Luiz da Sequeira Oliva apresentada à Academia Real das Ciências de Lisboa, provavelmente em finais do século XVIII. O trabalho (nunca publicado) intitulado "Algumas observações sobre a existência do salitre entre nós" 38 , enfatiza a abordagem teórica. Nessa memória, podemos reconhecer a mesma explicação dada por Couto para a formação do ácido nítrico quando Oliva diz que este ácido é formado pelo "azoto com a maior quantidade possivel de oxygeneo". Sendo esses princípios (oxigênio e azoto) formadores do "ar que respiramos; [...] se segue que existindo por toda a parte estes principios por toda parte pode concentrarse esta combinação" ... desde que fossem dadas as circunstâncias necessárias à formação do composto. Assim, baseando-se na regra das afinidades, Oliva propõe um método para a preparação do ácido nítrico, material fundamental para a posterior produção do salitre. A execução de tal processo evitaria, segundo o autor, o dispêndio de grande soma com a compra do produto no estrangeiro ${ }^{39}$.

\section{CONCLUSÕES}

Pudemos ver, através dos exemplos apresentados que, em Portugal e no Brasil, no tocante aos estudos sobre os compostos nitrogenados e, em especial, sobre o salitre, não faltou empenho dos então chamados naturalistas na execução dos trabalhos práticos - aí incluídos os trabalhos nas fábricas - e na elaboração teórica. Conhecedores das discussões levadas nos principais centros da Europa, foram capazes de propor explicações para cada um dos casos com que se defrontaram. As dificuldades, as indecisões e as confusões enfrentadas não foram diferentes das expostas por outros "químicos" em outras partes. Estavam, sem dúvida, sintonizados com seu tempo.

Verificamos, entretanto, que situações a contragosto dos homens da ciência difucultaram seus projetos. Assim, para analisar o projeto de institucionalização das ciências em Portugal e no Brasil não basta verificar se as idéias discutidas estavam no passo do que se realizava nos grandes centros. Nos vários casos apresentados deparamo-nos, uma vez mais, com a elaboração de trabalhos que, mesmo tendo incorporado as idéias mais recentes da Química, não encontraram a divulgação necessária que teria contribuído para o estabelecimento das ciências no Reino português. Juntem-se a isso as querelas políticas de grupos com interesses divergentes atuando a muitas milhas de distância, e teremos um quadro de contingências onde o sucesso acaba por ser raro.
Não fosse assim, talvez Augusto Fausto de Souza tivesse uma situação diferente a reportar em 1872 "sobre a conveniência de serem explorados os jazigos de salitre de Minas Gerais". Ele nos informa que o salitre então utilizado no Brasil vinha principalmente dos jazigos naturais e grutas de vários países do oriente e da produção química realizada em países europeus ${ }^{40}$.

Em nosso país, a produção de salitre teria sido abandonada, segundo nos relata Souza, por falta de conhecimento técnico na extração e no transporte do material. Acontece que o salitre era transportado em sacos ou bruacas (sacos de couro) em lombos de animais até as fábricas de pólvora. Era uma viagem que durava vários dias sob sol e chuva. Mais água passava pelos recipientes durante as travessias dos rios. No cômputo final, ao se determinar o preço do salitre, os produtores queriam compensar o que haviam perdido para as águas. Dessa forma, o salitre de Minas Gerais acabava custando muito mais do que o importado. Souza sugere ao governo retomar a produção do salitre e elevar "os direitos de importação do salitre estrangeiro" para conseguir "criar uma indústria que, não só suprirá desse artigo o mercado do Império, como será um novo ramo de exportação que produzirá grossas quantias”, acrescenta $^{41}$.

Em 1872 estava-se propondo, uma vez mais, a atuação de pessoas competentes, munidas dos necessários conhecimentos - químicos entre outros - para a realização das análises assim como para propor o equacionamento dos procesos industriais que permitissem finalmente dar um curso adequado à extração e à preparação de uma matéria-prima fundamental para diversas atividades. Ou seja, estava-se novamente no ponto de partida, como se quase dois séculos de estudos e trabalhos na área da produção de salitre não tivessem deixado marcas...

\section{AGRADECIMENTOS}

Agradeço à CAPES pela concessão de uma bolsa-sanduíche entre 1992-3 - que permitiu a pesquisa em solo português - e à FAPESP, pela bolsa de Pós-Doutorado, entre 1997-99.

\section{REFERÊNCIA}

1. Ver R. Amaible, "Lavoisier et la Révolution Poudrière", in Michelle Goupil, Lavoisier et la Révolution chimique, Acte $d u$ Colloque, Paris, 4 e 5 de dezembro de 1989, Paris, SABIX/École polytechnique, 1992, pp. 239-248. Se a expressão "revolução da pólvora", talvez, pudesse ser considerada exagerada, o fato de ter sido enunciada num trabalho publicado nas Actas de um colóquio significativo, denota a importância dos trabalhos sobre os explosivos.

2. Ver a esse respeito, A.M. Amorim da Costa, Primórdios da Ciência Química em Portugal, Lisboa, Inst. Cult. e Língua Portuguesa, 1984, pp. 77-81. Entretanto, outros estudos relativos aos compostos de nitrogênio e à pólvora foram realizados anteriormente aos de Sobral. Poderíamos citar a memória de Domingos Vandelli (1730-1816): «Varias observações de Chimica, e Historia natural», Memorias da Academia Real das Sciencias de Lisboa, 1(1797): 259-61, em que, uma das partes é denominada, justamente, "Mehodo de acrescentar a força á pólvora".

3. Ver, por exemplo, a carta do Provedor da Casa da Moeda de 28 de feverreiro de 1808, António Silvério de Miranda, endereçada ao Ministro da Fazenda, expondo os problemas da falta de salitre, ao mesmo tempo em que solicita que lhe sejam mandados alguns quintais (cada quintal correspondia a uma arroba) do material. Livro de Registo da Casa da Moeda de Lisboa, vol. 12, fls. 86r e 86v. Suas solicitações não se restringem a esta carta, pois, dois meses mais tarde, muito bem informado, Miranda pede que lhe seja enviada uma quantidade de "Salitre negro" que se encontrava no Arsenal do Exército e que não servia para a produção da 
pólvora por ser considerado "de inferior qualidade para o ministerio a que se destina". Ver Livro de Registo, vol. 12, fl. 88r; nesse livro podemos ler outras solicitações de salitre para manuseio de metais numa época em que importava mais fabricar pólvora; ver, outros documentos copiados nos fls. $100 \mathrm{v}, 104 \mathrm{v}$ e $109 \mathrm{v}-110 \mathrm{r}$.

4. No incêndio, também seus livros e papéis foram queimados (entre eles, o manuscrito do compêndio que estava redigindo há pelo menos uma década para o curso de Química), perdendo-se para sempre os documentos que poderiam ajudar a compor sua história. Ver Amorim da Costa, op. cit., pp. 77-81.

5. Ver, de nossa autoria, As ciências em Portugal e no Brasil (1772-1822): o texto conflituoso da Química, São Paulo, EDUC/FAPESP, 1997, principalmente o Cap. IV, pp. 151-90.

6. "Instruções passadas ao naturalista Alexandre Rodrigues Ferreira sobre o roteiro de viagens...", s.d. 21 fls., Arquivo do Instituto de Estudos Brasileiros, Coleção Lamego, Cod. 101, A8.

7. Mais detalhes sobre o processo podem ser vistos em José Martins da Cunha Pessoa, "Memória sobre o Nitro, e utilidades que dele se pode tirar", Memorias Economicas da Academia Real das Sciencias de Lisboa, tomo IV, Lisboa, Tipografia da Academia, 1812, reimp. Lisboa, Banco de Portugal, 1991, pp. 159-73. A lixiviação - que ocorre pela adição de água - tem como objetivo a separação, pela dissolução, dos componentes solúvies, entre eles, o salitre. A adição de cinzas e potassa (em alguns casos, adicionava-se uma ou outra) intercalando as camadas de terra visava a obtenção de uma quantidade maior de salitre. Podemos hoje dizer que a cinza e potassa reagem com os nitratos de cálcio e magnésio presentes nas "terras", produzindo o nitrato de potássio.

8. Ver nosso texto, As ciências em Portugal e no Brasil, op. cit., pp. 169-90.

9. Tendo se ocupado em publicar trabalhos de outros autores, sua grande obra, entretanto, a Flora Fluminense, só viria a público quase um século depois e, mesmo assim, mutilada. Como exemplos desses trabalhos enviados a Veloso, temos a carta de Frei Manuel Arruda da Câmara (1752-1810). Na missiva Câmara relata as atividades que então realizava na pesquisa de salitre, minas de ferro, ouro, pedras preciosas, petróleo etc. «Carta de Manoel Arruda da Camara ao Frei José Conceição Velloso», Recife, 24 de junho de 1799, onde refere-se a memórias enviadas a D. Rodrigo de Sousa Coutinho, e dá conta de «observações sobre algodão, anil e outros serviços e intrigas.» Museu Paulista, Arquivo José Bonifácio, D275.

10. Frei José Mariano da Conceição Veloso, Alographia dos alkalis fixos vegetal ou potassa, mineral ou soda e dos seus nitratos segundo as melhores memórias estrangeiras, Lisboa, Of. Simão Thadeo Ferreira, 1798; Mineiro do Brasil melhorado pelo conhecimento de mineralogia e metalurgia e das ciencias auxiliares, Lisboa, Of. António Rodrigues Galhardo, 1801; O Fazendeiro do Brasil, melhorado na Economia Rural dos Generos já cultivados, e de outros que se tem escrito a este assunto, coligido de memorias estrangeiras, Lisboa, Tip. Calcographica do Arco do Cego e Régia Of. Tipographica, 1798-1806, 10 vols.; Quinografia Portuguesa ou collecção de varias memorias, Lisboa, Of. João Procópio Corrêa da Silva, 1799.

11. Veloso, Alographia, op. cit., p. vii.

12. Quanto ao Fazendeiro do Brasil, por exemplo, sabe-se que quase toda a edição foi enviada ao Brasil para ser vendida por preço baixo ou fornecida aos lavradores. Entretanto, como observa um estudioso, "ficaram, por falta de interêsse, encalhadas nas secretarias do govêrno e os bichos acabaram devorando tudo. Mais tarde, já depois da
Independência, o que sobrou foi vendido como papel velho para fogueteiros.» Ver R.B. de Moraes, Livros e bibliotecas no Brasil Colonial, Rio de Janeiro, Liv. Técnicos e Científicos, 1979, p. 395

13. Fazem parte de seus escritos uma memória sobre uma erupção vulcânica do pico da Ilha do Fogo onde apresenta dados sobre a composição química dos materiais, ensaios econômicos e políticos sobre Cabo Verde, descrições de sua flora, memórias sobre o cultivo e produção do anil, encontrando-se pelo menos uma delas ainda manuscrita em arquivo brasileiro. Ver sobre Feijó e também suas publicações, em Ferraz, As ciências em Portugal e no Brasil, o p. cit., principalmente Cap. IV e Bibliografia.

14. A transcrição do documento pode ser lida na Publicações do Arquivo Nacional, vol. 48, p. 210, 1961.

15. Documento assinado por Feijó, Ceará, 15 de janeiro de 1803. Arquivo Histórico da Casa da Moeda de Lisboa, Maço 718, Q10.

16. Ibid, fl. 1r, nossa numeração. O trabalho que pretendia realizar se denominava também de "refinação", e era, basicamente, o processo que descrevemos acima, ou seja, a lixiviação (adição de água) da mistura de potassa, cinzas e "terra nitrogenada" (ricas em compostos nitrogenados), dando como produto o salitre.

17. Ibid., fl. $1 \mathrm{v}$.

18. Ibid., fl. 3v. Acompanha o processo, uma carta de Manoel Joaquim Garcia, Cirurgião-Mor da Capitania do Ceará, atestando a precária saúde de Feijó. $\mathrm{O}$ médico menciona a "atrabilis espalhada pela superfície da péle" que dificilmente seria curada por se repetirem "vários ataques provenientes pelos vapores dos acidos mineráes, que divagão pela athemosfera do Real Laboratorio do Salitre"; ver Manoel Joaquim Garcia, declaração de 12 de março de 1803, fl. 1r, Arquivo Histórico da Casa da Moeda de Lisboa, Maço 718, Q10.

19. Feijó, documento citado, Arquivo Histórico da Casa da Moeda de lisboa, fl 4r.

20. Ver de Pessoa, a "Memória sobre o nitro", op. cit. (nota 7), p. 162 e, ainda, G. Agricola, De Re Metallica, trad. americana de H.C \& L.H. Hoover, New York, Dover, 1950, p. 561-2, inclusive notas (trata-se de um texto do século XVI que faz a distinção entre os processos).

21. "Relatório de Charles Napion sobre reações químicas em vários minerais (em francês). (19-5-1801)”, Publicações do Arquivo Nacoinal, op. cit., p. 210; nossa tradução.

22. Napion vai ocupar o mesmo posto a partir de 1808 , no Rio de Janeiro.

23. Carta datada de 24 de março de 1803, Arquivo Histórico da Casa da Moeda, Maço 718, Q10, fl. 1r.

24. W. L. von Eschwege, Pluto Brasiliensis, $2^{\circ}$ vol., São Paulo/Belo Horizonte, Edusp/Itatiaia, p. 190.

25. Couto teria morrido na Ilha Terceira, em 1811, cumprindo pena devido à acusação de pertencer à maçonaria e de colaborar com os franceses invasores de Portugal; ver F. de Moraes, «Lista dos estudantes brasileiros na Universidade de Coimbra», Brasília, suplemento ao vol. IV, pp. 290-1; para mais detalhes sobre o trabalho de Couto, ver nosso texto, As ciências em Portugal e no Brasil, pp. 176-88.

26. Finalizada em 1799, essa memória seria publicada apenas na segunda metade do século seguinte existindo em várias cópias diferentes; José Vieira Couto, «Memória sobre a Capitania de Minas Geraes, seu território, seu clima, e produções metállicas: sobre a necessidade de estabelecer e animar a mineração decadente do Brazil: sobre o commercio e exportação dos metaes, e interesses régios; com um appendice sobre os diamantes e o nitro natural», Rev. Inst. Hist. Geog. Bras., 11(1874), pp. 289-335. A mesma memória foi republicada com estudo crítico, transcrição e pesquisa histórica de J. F. Furtado, Belo Horizonte, 
Fundação João Pinheiro, Centro de Estudos Históricos e Culturais, 1994.

27. Ver a memória publicada em $O$ Auxiliador da Indústria Nacional, 1840, pp. 390 et seq.

28. Ibid., citação à p. 395 .

29. Ibid., p. 396.

30. Ibidem.

31. Conforme tratamos em nosso trabalho As Ciências em Portugal e no Brasil, op. cit., pp. 184-5, a antiga discussão sobre o natural e o artificial, que perpassa a argumentação de Couto, é exposta com o intuito de convecer os governantes da relevância de seus projetos.

32. Couto, «Memória sobre as salitreiras de Monte Rorigo", op. cit., p. 399.

33. Ibid., pp. 401 e seq.
34. Ibid., p. 399-400.

35. Ibid., p. 402-3.

36. Ibid., p. 399-400.

37. Publicada por Frei J. M. C. Veloso, Lisboa, Tipografia do Arco do Cego, 1800; sobre esse autor e suas publicações, ver C. A. L. Filgueiras, «João Manso Pereira, químico empírico do Brasil Colonial», Química Nova, 16, pp. 155-60

38. Manuscrito da Academia das Ciências de Lisboa, Ms Azul, 374, tomo 2, manuscrito 26.

39. Ibid, fl. 304

40. "Memória de Augusto Fausto de Souza sobre a conveniência de serem explorados os jazigos de salitre de Minas Gerais. (21-6-1872)", Publicação do Arquivo Nacional, vol. 48 (1961), pp. 246-9.

41. Ibid., p. 247. 